\title{
EDITORIAL
}

\section{Jennifer Stephenson}

Macquarie University, Sydney, Australia

The last weekend in September saw the successful national conference for AASE. I, among others, was inspired by the keynote address from Ed Kame'enui, 'The challenges of all and each for scientifically based special education research: Ode to Pluto and other minor stars.' Ed made a passionate case for basing educational practice on sound scientific research and the necessity for dissemination and technical assistance as research is moved into practice. Other keynotes and associated workshops played their part in the dissemination of research-based practice in the areas of school-wide positive behaviour support (Tim Lewis), selfregulation and strategy instruction (Lorraine Graham and David Paterson) and evidence-based communication strategies for students with complex disabilities (Julie Hook). A wide range of other presentations provided teachers with information and practical examples illustrating evidence-based practices.

Three of the refereed conference papers are published in this issue of AFSE. The first, by Meree Reynolds, Kevin Wheldall and Alison Madelaine, reports on pilot studies on the effectiveness of MINILIT, a reading intervention for young at-risk students. Iva Strnadová and David Evans report on the coping strategies of mothers of children with an intellectual disability, and Lorraine Graham, Anne Bellert and John Pegg discuss learning difficulties in mathematics and the QuickSmart intervention aimed at students in the middle-school years who have difficulties in numeracy.

As well as these conference papers, Sung-Jin Hong and Coral Kemp report on a comparison of activity-based instruction and didactic instruction to teach sight words to young children with developmental delays attending a child care centre. The study by Jerry Ford examines teacher perceptions of the supports for students with disabilities and behaviour problems. Teachers provided information on the nature of the behaviour problems they dealt with, the supports that were available to them and their recommendations for the provision of effective supports. Chi-Cheng Wu and Linda Komesaroff provide a provocative discussion of inclusion in Victoria, noting that the demand for support services expands as more students are formally identified as having special educational needs. Finally, there is a brief report by Tony Thomas that reports the results of a survey (with a $94 \%$ return rate) on the characteristics of teachers and executive staff in special schools in Victoria. The declining numbers of staff with special education qualifications that he reports raise some concerns about the ability of the state to provide suitably qualified leaders and teachers in schools for students with special educational needs in the future. 